\title{
Analysis of the Link of Student's with Pedagogical Practices during Isolation Social: Experience Report In-State Public Basic Education
}

\author{
Diogo Bonioli Alves Pereira ${ }^{1}$, Lígia Moraes De Matos Campos ${ }^{2}$, \\ Luis Antonio Monteiro Campos ${ }^{3}$
}

ORCID: https://orcid.org/0000-0001-9824-1811

ORCID: https://orcid.org/0000-0003-2607-6786

ORCID: https://orcid.org/0000-0002-2707-5593

\begin{abstract}
${ }^{1}$ Psychologist Ph. D. Student in Psychology (UFRJ/PPGP), master's in psychology (UCP), and Professor of Philosophy at SEEDUC-RJ Designated as Educational Advisor. Professor and coordinator of the Psychology course at Estácio de Sá University, Alcântara campus.

${ }^{2}$ Master's student in Administration and Educational Management at UAB, Professor of English Language at SEEDUC-RJ designated as Deputy Director, Management 2017-2020.

${ }^{3}$ Psychologist, Ph. D. in Psychology and is Coordinator of the Master's degree at UCP.
\end{abstract}

\begin{abstract}
This article quantitatively analyzed the link between students and the pedagogical practices of a primary education school in the state school of Rio de Janeiro, during the social isolation resulting from the state of community contamination of COVID-19. Access to the Google Classroom platforming the school's 2020 approval results was analyzed. This research hypothesizes that the initial classes of each segment tend to show less link to pedagogical activities because they are new students in the institution. To interpret the concept and results we used the theoretical framework of Cognitive Psychology and, in response to the data, we elaborated a descriptive statistic of the students' access to the digital platform by classes and Pearson's correlation to verify the variables students to measure the maintenance of the students' bond with the school. The results showed a decrease in the number of members of the Digital Platform, a weak correlation between new/old students with the maintenance of links with pedagogical tasks, and the little possibility that terminal classes tend to show higher quality in the links of students.
\end{abstract}

Keywords: school link, social isolation, school psychology, COVID-19

\section{Introduction}

MERS-CoV and SARS-CoV viruses make up the family of coronavirus very common in animals and with transmissions between them. However, on December 20 19 , in the city of Wuhan, Hubei, China, was identified and recorded the first's case of transmission of a new coronavirus when studying an outbreak of viral pneumonia. This time, the virus was able to infect humans and be transmitted with the same exponential capacity as between animals and was soon classified as COVID-19. In humans, COVID-19 can cause a severe and acute respiratory crisis, classified as Coronavirus syndrome, which has a very high lethal capacity. Later studies have classified hCoV-229E, OC43, NL63, and HKU1 viruses as human coronaviruses, which are therefore also causing the same syndrome (Huang et al., 2020) [ ${ }^{4]}$.

As of March 10, 2020, the World Health Organization (WHO) classified the human transmission of SARS-CoV2 as a pandemic and warned the world about individual behaviors and strategies of government interventions aimed at alerting and preventing mass contamination, because, given the nature of the virus, the rate of contamination and mortality put the maintenance of the economy in a state of attention, of life and, perhaps, of the human species (Jasarevic, $2020\left[^{5]}\right.$; WHO, 2020) [ ${ }^{8]}$.
On March 11, 2020, in Brazil, the Ministry of Health recognized the state of community transmission of COVID-19 and issued Ordinance No.356/2020 that operationalized Law No.13, 979/2020 adopting, for the first time in the country, the quarantine measure as recommended by the WHO (2020) [8] as a measure to guarantee and maintain health services. Following this logic, the State of Rio de Janeiro published Decree No.46, 973/2020, through which it suspended activities with the agglomeration of people for fifteen days, partialized through vacation public agencies (including schools), and regulated strict hygiene practices in private capital companies. After these, several other decrees renewed and/or reformulated social isolation.

To monitor the development of the pandemic in Brazil, the Ministry of Health (MS) created the Coronavirus Panel, a web tool that has daily updating through data from the Unified Health System (SUS) with the objective of monitoring, informing, and indicating the effects of strategies to combat COVID-19 by the national territory.

Until the first ten days of November 2020, the Coronavirus Panel informs or that 5, 590, 025 cases were recorded in Brazil and 161, 106 deaths. This means that there is a degree of viral incidence of 2660.1 per 100,000 inhabitants and the growing evidence of mortality of 76.7 people per 100, 000 inhabitants. With a focus we can analyze the southwest region that stands out for the

Volume 11 Issue 1, January 2022

www.ijsr.net

Licensed Under Creative Commons Attribution CC BY 
presentation of 73,261 cases of deaths, this number approaches the sum of all other regions, although it sustains the third highest mortality rate per 100,000 inhabitants of Brazil, that is, $82.9 \%$. In an even more specific look, we highlight Rio de Janeiro with the highest mortality rate in the southeast region, namely 120.2 deaths per 100, 000 inhabitants (Ministry of Health, 2020) ${ }^{7]}$.

In the municipality of São Gonçalo/RJ, the city where the school is located whose data we analyzed, at the peak of the data collection for this research, the Interactive Panel remained disabled between November 4th and November 11 th, 2020. However, in previous access, in the last week of October, in this city, 14, 077 accumulated cases, 777 deaths, and an index of 72 deaths per 100, 000 inhabitants.

In this panorama of contamination, mourning, and isolation, the central question that motivated our studies formed the following problem: factors that influence the maintenance or loss of the bond of students about school activities during the period of social isolation? The initial hypothesis is that the initial classes of each teaching segment have a fragility with the school, since they are new students in the school and, therefore, would have little connection with the institution, its rules, and specify pedagogical ages. To test this hypothesis, we surveyed the number of accesses of students on the Digital Classroom platform and submitted a descriptive statistic of the classes. And then, we surveyed new students in each class and tested a Pearson correlation to see if there is a covariance between the variables "new students" and "old students" with the " loss of bond"; and, finally, and final exploratory factor analysis to ascertain when correlation factors could be extracted in these three variables.

Initially, we present the numbering of the impacts of COVID-19, the legislation issued during this period, and the state's specificities for the directions of schools. For the interpretation of the data, we used cognitive psychology as a theoretical reference to the psychological bond and its influence and its effects on human involvement. The relevance of this study is to analyze how the bond of the students is established with the institution, because, having the social, personal, and institutional ties suspended by law, the intensity of the interest of maintaining the bond would demonstrate the greater valence of connection.

It is expected that this article is relevant to the board, technical-pedagogical group, teachers at the analyzed school, and schools with similar profiles for generalization of results. This study can also contribute to the knowledge of characteristics of a strong bond that will contribute to the formation of new forms of strategies for the development of students' links with activities.

\section{The Educational Context in the Period of Social Isolation}

The process of implementing emergency remote education in the state of Rio de Janeiro, due to the suspension of face-to-face classes and social isolation resulting from the Pandemic of the New Coronavirus (COVID-19), followed
Resolution No.5843 of May 11, 2020, published by the secretary of education of the time, Pedro Fernandes. The document guided the units that are part of the SEEDUC (State Department of Education) network on the development of non-face-to-face school activities and regularization of the functional life of employees if they remain the isolation measures provided for by the state authorities as prevention and combating COVID-19.

In line with the protocol released by the WHO, the Brazilian Ministry of Health, and the State Health Secretariat, Rio de Janeiro complied with the guidelines of social isolation and to reduce the possible impacts on students' learning, the school-student relationship, and future educational losses, the secretariat employed an Action Plan that meets the Resolution of the State Council of Education No.376 of March 23, 2020, the Law of Guidelines and Bases of National Education (LDB 9394/96) and Provisional Measure No.934 of April 1, 2020. Thus, respectively, the first document guided the development of non-face-to-face activities. The second established the guidelines and bases of national education and the latter constituted exceptional norms on the school year of basic education and higher education resulting from the measures for the chartering of COVID 19.

The action plan prepared by SEEDUC guide all the activity to be performed by teachers, students, pedagogical staff, and the management team of this secretariat during the period of absence. Thus, the Google, The classroom platform was adopted as an official virtual classroom for the teacher to conduct the teaching process, preserving his pedagogical autonomy. The choice for this feature was made by easy access, either by mobile devices or not, both for teacher and student. This virtual environment also provided numerous learning-facilitating tools, such as videos, interactive exercises, forms, and various applications.

In addition, printed materials were made available via the post office, called "Self-regulated" activities that were prepared by teachers of the network. In this pedagogical model, explanatory texts are presented, that is, the students themselves are stimulated to build their knowledge from the questions proposed in each curricular component. We emphasize that these handouts were based on THE SEEDUC Ordinance SUGEN No.419/2003, which determined standards for evaluating the school performance of students of the State Network of Rio de Janeiro, including, allowing them to be used in emergencies, as is the case of social isolation resulting from the pandemic.

Another resource used during social isolation was "CLASS IN TV", a program entitled SEEDUC IN THE AIR. The classes were recorded by teachers of the network with a predefined grid that would cover the main curriculum contents of each series as a way of supporting the use of the digital platform and not disconnecting from the habit of attending the class.

To assist teachers in the development of actions in an online environment, the education department also offered

Volume 11 Issue 1, January 2022 
the Training Course for these professionals, through an Education Day (Educator's Guide). In it, the teachers had opportunities to know various resources and applications to be used in their virtual classrooms.

SEEDUC also planned actions that could support teachers and other employees involved in the educational process to act in the face of these new proposals of remote interaction with students. Thus, a line of action of qualification for planned so that practices could be rethought from the consideration that the quality of this new way of doing education would require new managerial skills to promote, efficiently and creatively, the integration of efforts from teamwork to learning. The professional of our time of social isolation must increasingly specialize in innovation, creativity, imagination, and critical thinking.

Through legal and regulatory frameworks, federal opinions, resolutions, and state deliberations during the period of removal and after numerous possibilities of return, the secretary of education, through its current secretary Comte Bittencourt, finally published SEEDUC Resolution No.5879 of October 13, 2020, which was exceptional, complementary standards for the organization and restructuring of the offer of elementary and high school courses of the school year 2020. Through this document, crucial pedagogical actions were defined for the approval of students, as well as strategies to rescue students without access, to minimize school dropout. Thus, the resolution decided that except for the school year 2020, the results obtained will not cause disapproval and the return to face-to-face classes will happen only for the years of terminality, that is, for the classes of the 3rd Year of High School and NEJA-IV. A Municipal Decree of São Gonçalo no.325/20 sustained and ensured this resumption.

Emergency remote education that could serve an audience of adolescents without cognitive readiness and distance learning skills showed a profile of a new teaching professional who could meet the demands led us to agree with Alonso (1985, p.6) [ ${ }^{1]}$ who tells us that the teacher should becomes an effective professional, as opposed to the person that only makes thinks bureaucratic employee; this professional will have to be seen as someone who is not ready, finished, but in constant training; An independent professional with autonomy to decide on your work and your needs; Someone who is always in search of new answers, new referrals to his work and not simply a fulfilling task and mechanical executor of higher orders and finally someone who has his eyes for the future and not for the past.

Regarding the school studied, the effort to maintain the bond by the institution happened at several levels: at the level of communication, the school opted for the creation of and groups in the popular messaging application via mobile/internet. In these groups, participate in the direction and pedagogical coordination, together with the students so that they could communicate about the pedagogical activities, collect submissions of activities, communications from the secretariat, other subjects that relate to the management, and request of care from the secretariat or educational guidance.

To increase interaction between students, the school created Canal Cedax. It is a YouTube channel where interviews were created with former students to narrate their experiences at school, their current professional activities and encourage the bond with the institution, as well as video classes and lectures of professionals. The channel ended its 2020 activities with 397 subscribers, 23 videos, and 257 hours of public viewing.

\section{Theoretical Reference}

Human development is a complex study "on changes related to age, behavior, thought, emotions and social relationships" (Bee, Boyd, Monteiro, 2011, p.26) [ ${ }^{2]}$. This field of knowledge has aroused numerous discussions and studies in the field of philosophy, sociology, and, especially in Cognitive Psychology, which we adopted as a reference for this study.

Among the theorists who stand out most about cognitive development, how much structure and processes, is the Swiss Jean Piaget [1896-1980] who built a theoretical scheme that is based on stages cognitive through the concepts of adaptation, assimilation, accommodation, balancing, and schemes. This theory postulates, mainly, that the child is an active participant in the development of his/her knowledge based on four factors. Two factors are part of an innate plan of the subject, refers to assimilation and accommodation; and two external factors, social transmission, and experience (Bee, Boyd, Monteiro, 2011) $[2]$.

In 1942, Piaget returns with the hypothesis that four factors determine the speed and duration of development: heredity, physical experience with objects, and social transmission and balance (Piaget, 2013) $\left[{ }^{10]}\right.$. If innate causes equip beings in their biological constitution, external causes provide cognitive variations of children in their development. In this scenario, school processes directly influence the speed of the child's cognitive development process, as well as fulfill the role that provides variations between subjects.

Social factors are links that directly influence the intellectual development of the human being who, since birth, is submerged in the social environment that acts on him. Thus, society grants a structure to the individual offering him a system constructed of signs that will constitute his thinking while offering him new values and an unlimited sequence of obligations, norms, and logic (Piaget, 2013) $\left[{ }^{10]}\right.$.

The social environment also enables interactions between individuals. These interactions allow the socialization of intelligent individuals, such as succession, so that the differences of individual mental structures indicate the influence of the exchange established with the social environment. The evidence of the need for a social bond transmitted by heat, the manifestation of warmth and smiles, present from the identical-motor stage for babies,

Volume 11 Issue 1, January 2022 
are more distinct when synchronous relationships in language acquisition, the child is not content to speak but makes "games" and jokes with words to symbolize their ideas.

This behavior demonstrates social transmission, that is, the educational factor, as a determining factor in the development process, which would be insufficient. Thus, there must be an external agent who tells the child what is necessary to learn. With the words of Piaget (1983, p.224) ${ }^{[9]}$, we agree that it is evident that for a transmission to be possible between the adult and the child or between the social environment and the educated child, it is necessary to have assimilation by the child of what they seek to inculcate from the outside.

According to Piaget (2013) ${ }^{[0]}$ are these relationships that the subject maintains a bond with those around him, that is, establish synchronous relationships that influence the acquisition of language and the way of thinking, while enabling instruction and note to the interlocutor making every moment the child's thoughts approved or challenged, enabling the discovery of an immense world of external thoughts and that will constitute it.

The construction of intelligence in this social environment also enables the learner to know the rules and morals. This evolution begins in the quint the stage of the motorsensory where consciousness still confuses the obligations with the regularities of the habit. Understanding the obligation in place of the simple habit removes the child from the intuitive thinking of deformed egocentrism through a relationship admitted to the action of the subject in an objective system (Piaget, 2013) [ ${ }^{10]}$.

In parallel to these cognitive processes, Piaget (2013) [ ${ }^{10]}$ still draws attention to the other problem of cognitive structure that also occurs in social relations, namely the affectivity that is characterized by its energetic compositions distributed over an object with positive or negative connections (Piaget, 1983) [ ${ }^{9]}$.

In Western culture, we adopt Greek philosophy as the origin of cognitive and rational formulations as a method of knowledge as opposed to mythical explanations. In this scenario stands out the figure of Socrates, who, in addition to breaking with the mythical interpretation and discourses of the sophists, inaugurates the possibility of knowledge through the dialogical action that produces the maieutic. In Socrates' dialogue with Polemarco, we watched the philosopher's attempt to return to his home saying that he could persuade Polemarco of it. The dialogue continues with Polemarco saying that it would be impossible for Socrates to persuade him if he refuses to listen to him. After that, he follows the praise of Socrates's endless dialogue and endless ironies. Here we have evidence of the need for the qualified bond as a path of the construction of knowledge and the Republic (Plato, 2011) $\left[{ }^{11]}\right.$.

For many decades, the school was considered as the leading social institution dedicated to social relationships aimed at human, cognitive and social development.

\section{Research Methodology}

The research was carried out in a school of the state public network, classified as Class A, located in the central region of the city of São Gonçalo/RJ, which serves children, adolescents, and adults, from the 6th grade of elementary school until the completion of high school, in the modality of Regular Education and New Education of Youth and Adults (NEJA), in the morning, afternoon and evening shifts. According to the official system of the student management network, the school registered, in 2020, 1936 students enrolled, 278 students no NEJA, 250 students the final grades of elementary school, and 1408 in regular high school.

Following the model of the current LDB, the analyzed school is dedicated, primarily, to the care of high school students, but by tradition, still hosts elementary school in the final grades. To better objectify the analysis of the data, only regular education was admitted, because it is a more homogeneous sample and, usually only dedicated to studies, so students who need to share their attention with work and /or with family responsibilities are rarely found. This sample circumscription was also adopted based on the observation that the night classes have a differentiated and singular set of regiments, maturity, differentiated workload, and distinct school periodization.

The first data of the research were obtained from the analysis of an indirect, unofficial, functional, and monitoring service documentation for the pedagogical team that, at the time, fulfilled the function of recording the daily access of each student in the Google Classroom Platform. This document generated the tables The difference to the Digital Platform per class, without the identification of students. There data source was the survey, student per student, which was marked the form of bond that the student established with the school, namely if he returned in person if he participates in the virtual environment offered if he received the handouts sent by the post office (self-regulated) or resolves the handout offered by the school. This second data source was named Active Search because if the student had not demonstrated any form of a bond, it should be located and assisted by the educational guidance sector. If the Active Search failed, it was up to the educational guidance to inform the Tutelary Councils of the proper competence and the Metropolitan competence of the school studied, under the care of the frequency monitoring sector (RAF). The last source of data was extracted by the institution, from the Final Minutes of the COC (class council), containing only the number of students "approved with continuity" or "retained", that is, approved with study debt s for the next year or disapproves. The first, they moved on to the next series, but the second should remain retained in the grade enrolled in 2020 .

For the accomplishment of this study, it was not necessary to submit to the Research Ethics Committee since it is a "research with a database, whose information is aggregated, without the possibility of individual identification" as shown in Resolution No.510 of April 7, 2016, in Paragraph One, item V, in which they provide for

Volume 11 Issue 1, January 2022 


\section{International Journal of Science and Research (IJSR) \\ ISSN: 2319-7064 \\ SJIF (2020): 7.803}

research that should not be registered and evaluated by the CEP/CONE system.

To test the hypothesis that the initial tur mas of the segments of each teaching tends to demonstrate a more fragile bond and the terminal classes a stronger bond, we had the analysis of the amplitude, variance, and the standard deviation of each class and the average of each shift.

To know if new students, regardless of class and followup, tend to manifest a more fragile bond with school activities and, if otherwise, former students tend to elicit a more consistent bond, we use the Active Search worksheet, after filling it out. We selected and quantified the old students of the new students by the numbering of the enrollment, the enrollments started with 2020, indicated new students in the network, on the contrary, students who exhibited a lower beginning than 2020, were understood as old in the network. After that, we performed Pearson's test and exploratory factor analysis to compare the loads and verify the hypothesis.

\section{Results and Discussions}

To test the hypothesis that initial grades tend to have the greatest evasion because they have most new students, a survey of the standard deviation and variance of class advance was performed; a correlation by Pearson's test between the bonds of freshmen and veterans and the losses of bonding and, finally, a quantitative analysis of the Coc's Final A-AS to know the number of students retained in the grade.

\section{Standard Deviation Test And Variance of The Decision Of The Terms}

To know the variability of access to the sample platform, we used the concept of amplitude (A), which "is the difference between the highest scores $(\mathrm{H}=$ high $)$ and the lowest $(\mathrm{L}=$ low) in a distribution" (Levin, Fox, Forde, 2012, p.98) [6]. The lower the variance, the greater the constancy in the access of students over the analyzed period, this is the same as saying that the frequency and access are constant over the days; on the contrary, the higher the variance, the greater the oscillation of the amount of access over the days analyzed.

The standard deviation ( $\mathrm{s}$ ) is the easiest way to interpret a variance because the value obtained by the standard deviation corresponds to the distance of any gross score of the sample mean, it is, a measure of the dispersion of the data around the sample mean. The higher the standard deviation, the better the distribution around the mean; while the lower the obtained value, the more condensed the values are in the mean (Levin, Fox, Forde, 2012) [ ${ }^{6]}$.

In this research, how we evaluated the adherence of a class through the amount of access to the platform in an interval of days, the greater the standard deviation, the greater constancy in the number of accesses of the students over the days analyzed, and the lower the standard deviation, the lower the constancy of access to the long days. Classes that have a small standard deviation may have been motivated to access by the need for evaluation, synchronous class, or school campaign.

We started the analysis with the data obtained from the Tables of Adherence to the Digital Platform per Day to produce statistical analyses. First, elementary school, which are exclusively no morning shift, with seven classes, in the four final grades, with uninterrupted dating from $05 / 06 / 2020$ to $10 / 08 / 2020$, with $n=98$, referring to the school attendance days registered by the institution (Table 1).

Table 1: Adherence to the Digital Platform per day-Elementary School

\begin{tabular}{|c|c|c|c|c|c|c||c|c||c|c|}
\hline & T601 & T701 & T702 & T801 & T802 & T901 & T902 & \multicolumn{2}{|c|}{ Misday } \\
\hline Number of Days (n) & 98 & 98 & 98 & 98 & 98 & 98 & 98 & 98 & 98 \\
\hline Average access per day & 5.786 & 11.469 & 8.786 & 9.367 & 13.235 & 11.561 & 14.153 & 10.622 \\
\hline Standard Deviation (s) & 2.617 & 3.767 & 3.247 & 3.912 & 4.721 & 4.329 & 3.933 & 3.789 \\
\hline Variance (A) & 6.851 & 14.190 & 10.541 & 15.307 & 22.285 & 18.744 & 15.471 & 8.053 \\
\hline Men c ilition & 0.000 & 0.000 & 0.000 & 0.000 & 0.000 & 4.000 & 5.000 & 1.285 \\
\hline Máximo & 10.000 & 19.000 & 15.000 & 17.000 & 23.000 & 22.000 & 23.000 & 18.429 \\
\hline \hline
\end{tabular}

The lowest variance (A), average access per day of elementary school, and standard deviation ( $\mathrm{s}$ ) are found in T601. This indicates that the sixth year has lower constancy of access over the days analyzed. Thus, the sixth year presented a peak of punctual and narrow access throughout these days. In the opposite, the ninth year contains the highest $s$ index of variance and average daily access. This means that it presented accesses with greater constancy over the days. In an overview, there is an increase in the number of activities as the activities progress, this is evident through the analysis of the mean $\mathrm{s}$ of accesses per day $(601=5,786 ; 701$ and $702=10,127$; 801 and 802=11, 301; 901 and 902=12, 857). It follows this to increase the variance. The standard deviation (s) presents a slight decrease in the stage of the ninth year.

We passed the analysis of high school, in the regular modality and excluding the night shift. The data of the 1 st year of high school are distributed in two shifts, being, one class in the full regime, six in the morning shift, and seven in the afternoon. There are fourteen classes. The date was uninterrupted between 29/04/2020 and 08/10/2020, accounting for 99 school days observed and the data were organized and separated according to the shifts, being T1001, the integral; the range from 1002 to 1007 (Table

Volume 11 Issue 1, January 2022 www.ijsr.net 


\section{International Journal of Science and Research (IJSR) ISSN: 2319-7064 \\ SJIF (2020): 7.803}

2), for the morning shift; and classes between 1008 and

1014 (Table 3), in the afternoon.

Table 2: Adherence to the Digital Platform per day-1st Year of High School Morning

\begin{tabular}{|l||l|l|l|l|l|l|l|l|l|}
\hline & T1001 & T1002 & T1003 & T1004 & T1005 & T1006 & T1007 & Average \\
\hline Number of Days (n) & 99 & 99 & 99 & 99 & 99 & 99 & 99 & 99 \\
\hline Average access per day & 10.343 & 8.960 & 7.182 & 8.828 & 9.828 & 9.869 & 11.778 & 9.408 \\
\hline Standard Deviation (s) & 3.975 & 4.307 & 3.674 & 3.761 & 3.744 & 4.679 & 4.570 & 3.685 \\
\hline Variance (A) & 15.799 & 18.549 & 13.497 & 14.144 & 14.021 & 21.891 & 20.889 & 13.581 \\
\hline Minimal & 0.000 & 0.000 & 0.000 & 0.000 & 0.000 & 0.000 & 0.000 & 0.000 \\
\hline Maximum & 23.000 & 20.000 & 21.000 & 18.000 & 17.000 & 25.000 & 23.000 & 20.170 \\
\hline
\end{tabular}

Table 3: Adherence to the Digital Platform per day-1st Year of High School Afternoon

\begin{tabular}{|c||c|c|c|c|c||c|c|c|}
\hline & T1008 & T1009 & T1010 & T1011 & T1012 & T1013 & T1014 & Average \\
\hline Number of Days (n) & 99 & 99 & 99 & 99 & 99 & 99 & 99 & 99 \\
\hline Average access per day & 6.960 & 12.051 & 6.263 & 13.576 & 12.424 & 5.263 & 12.919 & 9.922 \\
\hline Standard Deviation (s) & 2.208 & 3.618 & 3.403 & 3.058 & 3.308 & 2.063 & 3.672 & 3.047 \\
\hline Variance (A) & 4.876 & 13.089 & 11.583 & 9.349 & 10.941 & 4.257 & 13.483 & 5.691 \\
\hline Minimal & 0.000 & 0.000 & 0.000 & 0.000 & 0.000 & 0.000 & 0.000 & 0.000 \\
\hline Maximum & 16.000 & 21.000 & 14.000 & 20.000 & 20.000 & 11.000 & 20.000 & 17.429 \\
\hline
\end{tabular}

The variance of the morning and afternoon classes have high irregularity, with peaks of decreased growth, being T1003 $(\mathrm{A}=13,497$ and $\mathrm{s}=3,674)$ and $\mathrm{T} 1013(\mathrm{~A}=4,876$ and $s=2,208$ ) being the $s$ that indicated, respectively, the highest and lowest frequency variance to the digital platform. The variance is much lower in the afternoon shift, even if the average access between both shifts is very close. Analyzing both classes, we have $\mathrm{M}=9,665$; $\mathrm{s}=3,379$ and $\mathrm{A}=9,636$.
The 2nd year of high school is observed in two shifts: morning and afternoon. The dating was uninterrupted from $28 / 04 / 2020$ to $02 / 10 / 2020$, accounting for 99 school days observed and the data were organized and separated according to the shifts, the interval from 2001 to 2006 (Table 4) in the morning shift; and the classes between 2007 and 2011 (Table 5), in the afternoon. There are eleven classes.

Table 4: Adherence to the Digital Platform per day-2nd Year of High School Morning

\begin{tabular}{|c||c||c|c||c|c||c||c|}
\hline & T2001 & T2002 & T2003 & T2004 & T2005 & T2006 & Average \\
\hline Number of Days (n) & 99 & 99 & 99 & 99 & 99 & 99 & 99 \\
\hline Average access per day & 21.051 & 20.010 & 18.939 & 18.949 & 10.121 & 9.960 & 16.505 \\
\hline Standard Deviation (s) & 4.566 & 4.995 & 4.744 & 6.043 & 3.354 & 2.853 & 4.426 \\
\hline Variance (A) & 20.844 & 24.949 & 22.506 & 36.518 & 11.250 & 8.141 & 14.661 \\
\hline Minimal & 11.000 & 0.000 & 0.000 & 0.000 & 0.000 & 0.000 & 1.833 \\
\hline Maximum & 32.000 & 30.000 & 33.000 & 31.000 & 21.000 & 18.000 & 27.500 \\
\hline
\end{tabular}

Table 5: Adherence to the Digital Platform per day-2nd Year of High School Afternoon

\begin{tabular}{|c||c|c|c|c|c|c|}
\hline & T2007 & T2008 & T2009 & T2010 & T2011 & Average \\
\hline Number of Days (n) & 99 & 99 & 99 & 99 & 99 & 99 \\
\hline Average access per day & 9.687 & 5.434 & 6.909 & 6.707 & 7.152 & 7.178 \\
\hline Standard Deviation (s) & 3.498 & 3.479 & 2.339 & 2.745 & 2.417 & 2.896 \\
\hline Variance (A) & 12.238 & 12.105 & 5.471 & 7.536 & 5.844 & 5.254 \\
\hline Minimal & 0.000 & 0.000 & 0.000 & 0.000 & 0.000 & 0.000 \\
\hline Maximum & 22.000 & 18.000 & 16.000 & 16.000 & 13.000 & 17.000 \\
\hline
\end{tabular}

Statistically, the 2nd year of Regular High School presents a considerable difference in the mean of the accesses between morning $(\mathrm{M}=16.505)$ and late $(\mathrm{M}=7.178)$, with the morning shift more than double the average access. The average variance stake in shifts also accompanies this same logic, with the morning $(14,661) 64 \%$ more of the variance than the afternoon shift $(5,254)$. Analyzing both classes, we have: $\mathrm{M}=11,841 ; \mathrm{s}=3.661$ and $\mathrm{A}=9.957$ th.
The 3rd year of high school is presented in two shifts: morning and afternoon. The dating was uninterrupted from $07 / 05 / 2020$ to $06 / 10 / 2020$, accounting for 94 school days observed and organized separately according to the shifts being, the interval from 3001 to 3006 (Table 6) in the morning shift and, the classes between 3007 and 3011 (Table 7) in the afternoon. There are 11 classes.

Volume 11 Issue 1, January 2022 www.ijsr.net

Licensed Under Creative Commons Attribution CC BY 


\section{International Journal of Science and Research (IJSR) ISSN: 2319-7064 \\ SJIF (2020): 7.803}

Table 6: Adherence to the Digital Platform per day- $3^{\text {rd }}$ Year of High School Morning

\begin{tabular}{|c||c|c|c|c|c|c|c|}
\hline & T3001 & T3002 & T3003 & T3004 & T3005 & T3006 & Average \\
\hline Number of Days (n) & 94 & 94 & 94 & 94 & 94 & 94 & 94 \\
\hline Average access per day & 16.979 & 14.957 & 20.628 & 19.479 & 14.330 & 13.500 & 16.646 \\
\hline Standard Deviation (s) & 3.347 & 4.045 & 8.289 & 2.585 & 4.834 & 3.470 & 4.428 \\
\hline Variance (A) & 11.204 & 16.364 & 68.709 & 6.682 & 23.363 & 12.038 & 12.892 \\
\hline Minimal & 10.000 & 6.000 & 0.000 & 13.000 & 7.000 & 0.000 & 6.428 \\
\hline Maximum & 24.000 & 23.000 & 33.000 & 24.000 & 26.000 & 22.000 & 25.333 \\
\hline
\end{tabular}

Table 7: Adherence to the Digital Platform per day-3rd Year of High School Afternoon

\begin{tabular}{|c|c|c|c|c|c|c|}
\hline & T3007 & T3008 & T3009 & T3010 & T3011 & Average \\
\hline Number of Days (n) & 94 & 94 & 94 & 94 & 94 & 94 \\
\hline Average access per day & 15.255 & 7.787 & 12.309 & 11.553 & 8.117 & 11.004 \\
\hline Standard Deviation (s) & 3.704 & 1.906 & 3.183 & 3.008 & 2.309 & 2.822 \\
\hline Variance (A) & 13.719 & 3.632 & 10.130 & 9.046 & 5.330 & 5.527 \\
\hline Minimal & 9.000 & 4.000 & 6.000 & 5.000 & 0.000 & 4.800 \\
\hline Maximum & 28.000 & 13.000 & 23.000 & 18.000 & 13.000 & 19.000 \\
\hline
\end{tabular}

In the last year of high school, we have an average of higher access in the morning shift and a lower variance in the afternoon shift. Although the means of both are close, the distance from the variance indicates an oscillation in the accesses. Analyzing both classes, we have: $M=13$, 825; $s=3,625$ and $A=9,209$.

Observing the initial series of each segment, we can notice increasing average access to the platform per day (M) throughout the school cycle. Thus, we can affirm that the initial classes of each segment have less adherence and bond with the school and, as the series advances, showed an increase in access to digital activities, demonstrating greater growth of the link to digital activities.
Although it is evident the increasing adherence of students throughout the serialization, in both segments, better data was needed to analyze whether freshmen students were more biased to elicit more fragile bonds. Andon $11 / 23 / 2020$ the school completed a survey that identified the number of students who did not do any pedagogical activity on the online platform or other parallel activity to conduct an active search on students who have not expressed any form of link with the school. This data was organized in Table 8 that contains the number of students enrolled up to that time, the number of new and old students per class. After that, the percentage of bond losses in each class and the sum of the items raised were calculated.

Table 8: New, old and loss of links by classes in regular education

\begin{tabular}{|c|c|c|c|c|c|}
\hline Class & $\begin{array}{c}\mathrm{N} \\
\text { Students }\end{array}$ & $\begin{array}{c}\mathrm{N} \\
\mathrm{New}\end{array}$ & $\begin{array}{c}\mathrm{N} \\
\text { Ancient }\end{array}$ & $\begin{array}{c}\mathrm{N} \\
\text { They losttheV ículo }\end{array}$ & \% Losses \\
\hline 601 & 30 & 22 & 8 & 7 & 23,3 \\
\hline 701 & 32 & 4 & 28 & 5 & 15,6 \\
\hline 702 & 32 & 21 & 11 & 6 & 18,8 \\
\hline 801 & 37 & 0 & 37 & 8 & 21,6 \\
\hline 802 & 38 & 16 & 22 & 8 & 21,1 \\
\hline 901 & 40 & 1 & 39 & 8 & 20 \\
\hline 902 & 41 & 18 & 23 & 4 & 9,8 \\
\hline 1001 & 29 & 6 & 23 & 3 & 10,3 \\
\hline 1002 & 32 & 2 & 30 & 1 & 3,1 \\
\hline 1003 & 39 & 9 & 30 & 3 & 7,7 \\
\hline 1004 & 40 & 20 & 20 & 0 & 0 \\
\hline 1005 & 37 & 16 & 21 & 9 & 24,3 \\
\hline 1006 & 37 & 28 & 9 & 8 & 21,6 \\
\hline 1007 & 38 & 22 & 16 & 7 & 18,4 \\
\hline 1008 & 40 & 20 & 20 & 12 & 30 \\
\hline 1009 & 40 & 33 & 7 & 7 & 17,5 \\
\hline 1010 & 38 & 3 & 35 & 12 & 31,6 \\
\hline 1011 & 38 & 27 & 11 & 4 & 10,5 \\
\hline 1012 & 33 & 24 & 9 & 8 & 24,2 \\
\hline 1013 & 36 & 26 & 10 & 12 & 33,3 \\
\hline 1014 & 38 & 25 & 13 & 8 & 21,1 \\
\hline 2001 & 38 & 2 & 36 & 5 & 13,2 \\
\hline 2002 & 38 & 0 & 38 & 1 & 2,6 \\
\hline 2003 & 38 & 0 & 38 & 3 & 7,9 \\
\hline
\end{tabular}

Volume 11 Issue 1, January 2022 www.ijsr.net 
International Journal of Science and Research (IJSR)

ISSN: 2319-7064

SJIF (2020): 7.803

\begin{tabular}{|c|c|c|c|c|c|}
\hline 2004 & 38 & 0 & 38 & 1 & 2,6 \\
\hline 2005 & 38 & 10 & 28 & 2 & 5,3 \\
\hline 2006 & 38 & 15 & 23 & 3 & 7,9 \\
\hline 2007 & 38 & 1 & 37 & 5 & 13,2 \\
\hline 2008 & 35 & 0 & 35 & 6 & 17,1 \\
\hline 2009 & 33 & 1 & 32 & 6 & 27,3 \\
\hline 2010 & 32 & 4 & 28 & 4 & 18,8 \\
\hline 2011 & 20 & 8 & 12 & 1 & 20 \\
\hline 3001 & 39 & 0 & 39 & 1 & 2,6 \\
\hline 3002 & 39 & 0 & 39 & 3 & 7,9 \\
\hline 3003 & 38 & 0 & 38 & 3 & 7,9 \\
\hline 3004 & 38 & 0 & 38 & 4 & 10,5 \\
\hline 3005 & 38 & 0 & 38 & 3 & 9,4 \\
\hline 3006 & 28 & 6 & 22 & 3 & 0 \\
\hline 3007 & 32 & 2 & 30 & 0 & 9,7 \\
\hline 3008 & 25 & 0 & 25 & 3 & 34,5 \\
\hline 3009 & 31 & 0 & 31 & 10 & 14,5 \\
\hline 3010 & 26 & 2 & 24 & 219 & \\
\hline 3011 & 29 & 3 & 26 & & \\
\hline Total & 1514 & 397 & 1117 & & \\
\hline
\end{tabular}

In 2020, the classes analyzed brought 397 new students to the state school system identified through their enrollments, which begin with 2020 (. . .). In elementary school we followed a close number of students' admission, $60 X=22 ; \quad 70 X=25 ; \quad 80 X=16$ and $90 X=19$. Another evidence is the percentage of loss of oscillating bonds throughout elementary school in the following proportion: $60 \mathrm{X}=23.3 \% ; 70 \mathrm{X}=17.1 \% ; 80 \mathrm{X}=21,3 \%$ and $90 \mathrm{X}=14,8 \%$.

In high school, the 1st year of high school is also a great gateway for new students to the statement work. A total of 261 students were enrolled in new enrollments, with a little more than half of the students coming from the state or the school itself. The percentage losses according to the series were: 1 st Year $=18.1 \%$; 2nd Year $=12.4 \%$ and $3 \mathrm{rd}$ Year $=9.8 \%$.

Correlation of the bond between freshmen and veterans

To better analyze the hypothesis that new students tend to lose their link with pedagogical activities, Pearson's correlation test was performed with the data in Table 8 to evidence the existence of new students and old students with the loss of bonding. The correlation analysis returned what we showed below:

Table 9: Pearson's Correlation

\begin{tabular}{|c||c||c|c|c|c|c|c|}
\hline Variables & & N New & Ancient N & \multicolumn{2}{|c|}{ N They lost the bond } \\
\hline N They lost the bond & Pearson's r & 0.406 & $* *$ & -0.350 & $*$ & - & \\
\hline & p-value & 0.007 & & 0.021 & & - & \\
\hline & $* \mathrm{p}<.05, * * \mathrm{p}<.01, * * * \mathrm{p}<.001$ \\
\hline
\end{tabular}

It is noted that the correlation of New $\mathrm{N}$ and Old $\mathrm{N}$ is inversely proportional to the loss of the link. We observed that at the significance level (p-value) returned a high value for former students who lost the bond, that is, 2 out of 100 , they would lose the bond by chance. While the correlation load between new students and loss of bonds keeps a correlational load still negligible and with a low significance. Therefore, there is no consistent correlation between the student being young and losing the bond and such a phenomenon could be a chance.

For further investigation, an Exploratory Factor Analysis test was performed that returned only one correlational factor (Factor 1), namely, a correlation between New $\mathrm{N}$ and Old $\mathrm{N}$, evidencing no significant correlation between New $\mathrm{N}$ with $\mathrm{N}$ Lost Bonds or between $\mathrm{N}$ Olders and $\mathrm{N}$ Lost Bonds.

Table 10: Loading Factors

\begin{tabular}{|c|c|c|}
\hline & Factor 1 & Uniqueness \\
\hline N New & 1.000 & 0.000 \\
\hline Ancient N & -0.893 & 0.203 \\
\hline N They losttheV ículo & & 0.840 \\
\hline \hline \multicolumn{2}{|c|}{ Note: Applied ProMax rotation method } \\
\hline
\end{tabular}

Soon after the school identified the 219 students with lost ties, that is, $11.3 \%$ of the school's quantity in 2020 followed the attempt of personal contact by the pedagogical technical staff of the school that soon and demonstrated effective and necessary to rescue the student's bond with the institution.

Volume 11 Issue 1, January 2022 www.ijsr.net 
After direct action, three students were detected who have transferred from the school pending documents, that is, they did not request the school transfer and were already studying at another educational institution. After that, 104 bonds were reestablished and 115 remained with a lost bond, which was later counted as "retained" in the school series, representing $5.94 \%$ of "disapproval".

Of these students who lost ties resulted in 39 FICAIS sent to the Guardianship Council; and, 89 AMI, delivered to The Metropolitan, both according to SEEDUC Resolution No.5533, of July 31, 2017.

\section{Final Considerations}

In a simple online chart, all classes, in both segments, exhibit a decrease in the support of the Google Classroom Platform, however, it is not enough to interpret and analyze the factors that influence the maintenance or loss of the link of students with school activities in this pandemic period.

The increase in the average access in the classes of the elementary class shows that the link with pedagogical activities tends to increase as the serialization progresses. Readiness for learning and independence in the use of internet access devices may influence the outcome, but further research will be needed to do so. The same crescent is noted in high school. There is an increase in the mean of accesses along with the advance of the serialization; the variations between the standard deviation and amplitude are discrete.

From the analysis of the active search survey of the school, it was evidenced that the entry of new students is constant along the segment of elementary school and not only 6th grade, but a grade also that begins the cycle in the institution. The oscillation of the percentages of the bonds lost along the grade of elementary school is insufficient to confirm the hypothesis that the initial series have more fragile bones than as the subsequent series advance. On the contrary, the decrease in the percentage of losses throughout high school confirms the hypothesis.

When analyzing the justification of the hypothesis, namely that new students try to have weaker bonds than students veto years, Pearson's correlation demonstrated that the losses of the bond are proper to chance, rather than being a correlation with the variable's new students or former students. The exploratory factor analysis confirmed that the presence of only one factor and excludes the loss of bond as a variable that can be a correlation table.

In a statement, the hypothesis that the initial classes of each segment tend to exhibit less bonding is feasible, but not valid because they are caused by the students to be new or old in the institution.

Further research will be necessary to demonstrate the factors that corroborate the quality of adherence to the students' bond and that also cover the specificities of internet access and access devices in the construction of the student's bond with the institution.

\section{References}

[1] Alonso, M. (1985) Train teachers for a new school. São Paulo: Pioneer.

[2] Bee, H., Boyd, D., \& Monteiro, C. (2011) The developing child.12 ${ }^{\mathrm{a}}$ ed. Porto Alegre: Artmed.

[3] Brazil. (2020) Law No 13, 979/2020.

[4] Huang, C. et al. (2020) Clinical features of patients infected with 2019 novel coronavirus in Wuhan, China. The Lancet, v.395, n.10223, p.497-506, fev.2020.

[5] Jasarevic, T. (2020) Declaración de la OMS tras superarse los 100000 cases of COVID-19. Available in: <https://www.who.int/es/news/item/07-03-2020 who-statement-on-cases-of-covid-19-surpassing-100000>. Accessed: 3 Feb.2021.

[6] Levin, J.; Fox, J. A.; Forde, D. R. (2012) Statistics for humanities. Translation: Jorge Ritter.11th edition. São Paulo: Pearson Education do Brasil.

[7] Ministry Of Health. (2020) Coronavirus Brazil. Available in: <https: //covid. saude. gov. br/>. Accessed: 25 Oct.2020.

[8] WHO. (2020) Update of the covid-19 strategy. Geneva, Switzerland: IGO.

[9] Piaget, J. (1983) Problems of genetic psychology. Translation: Nathanael C. Clerk; Translation: Zilda Abujamra Daeir; Translation: Celia E. A. Di Piero. $2^{\text {to }}$ ed. São Paulo: Cultural April.

[10] Piaget, J. (2013) The psychology of intelligence. Translation: Guilherme João de Freitas Texeira. Petrópolis, RJ: Editora Vozes.

[11]Plato. (2011) The Republic. Translation: Pietro Nassetti. ${ }^{\text {ed. }}$ São Paulo: Martin Claret.

[12] Rio de Janeiro. (2020) Decree ${ }^{\text {No.46, 973/2020. }}$

\section{Author Profiles}

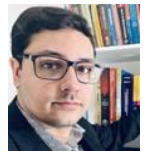

DIOGO BONIOLI ALVES PEREIRA, PhD student in Psychology at the Federal University of Rio de Janeiro (2021.2), Master's in Psychology at the Catholic University of Petrópolis (2019), Psychologist and Licentiate in Psychology at the Estácio de Sá University (2007/2008); Licentiate in Philosophy from at the Vez do Mestre (AVM-2012). Specialist in Systems Analysis, Management and Projects (UNESA-2009); Technologies in Education (PUC-Rio-2014) and School Management: Administration, Supervision and School Counselor (UCAM-2017). He was a professor at Universidade Estácio de Sá in the Graduate course in Psychology and coordinated the course. Worked as Supervisor of Specific Clinical Internship (SPA) in the Psychoanalysis. He is a psychoanalyst, member of the IF/FCL-Niterói. Teacher of the Philosophy at the Departamente of Education from Rio de Janeiro State (2012), he served as a School Counselor Teacher (2018-2021). Since 2009, he works with Clinical Psychology, Psychological, Neuropsychological and Cognitive Assessment for the school context and occupational health. Member of the Scientific Council and Reviewer/reviewer for the journal RECIMA21. He is a speaker and offers professional refresher courses in management, education and related areas for companies and schools. The research interests are in the themes of

Volume 11 Issue 1, January 2022 
Cognition Sciences, Social Cognition, Social Psychology, Thought and Language, School Psychology, Psychoanalysis and Psychotherapies.

\section{LÍGIA MORAES DE MATOS CAMPOS,}

Master's student in Education at Open University of the Lisboa. Graduated in Languages (Portuguese-English) at University Rio de Janeiro State (2000). Teacher at the Departament of Educacion from Rio de Janeiro State and held the position of School Director in the 2017-2020 management.

\section{LUIS ANTONIO MONTEIRO CAMPOS,}

Graduated in Agricultural Engineering from the Federal Rural University of Rio de Janeiro (1986), Graduated in Psychology from the Federal University of Rio de Janeiro (1992), Master's in Psychology from the Federal University of Rio de Janeiro (1996) and Ph. D. in Psychology from the University Federal of Rio de Janeiro (2001). Specialist in Logotherapy by the Brazilian Society of Logotherapy, specialist in Legal and Clinical Psychology by CFP. He was Health Unit Director for 8 years. He was Mental Health Coordinator of the Municipality of Duque de Caxias. He was President of the Municipal Anti-Drug Council of the municipality of Duque de Caxias for two consecutive terms. He was a Member of the Municipal Council for Social Assistance of the Municipality of Duque de Caxias. Member of the Municipal Council for the Rights of Children and Adolescents. Coordinator of the Adolescer Project with the FIA for eight years. He was Project Coordinator at UNDCP/UN. He was a member of the Regional Council of Psychology of Rio de Janeiro. Manager of the volunteer selection process for the 2007 PAN. Co-manager of the Rock in Rio 2011 volunteer selection process. Creator and one of the creators of Clickprofissão. He was Psychology Course Coordinator, Research Coordinator, Psychology Course Director, National Pedagogical Coordinator of Estácio's Psychology and Hospital Management Courses. He served on the Research Ethics Committee at the Universidade Estácio de Sá, Member of the Brazilian Society of Psychology, Member of the American Society of Psychology. He is currently licensed psychologist at the Municipality of Duque de Caxias and is a University Professor and Coordinator of the Master's Degree in Psychology at UCP and professor at PUC-RIO. Participant of the International Child Mental Health-Study Group (ICMH-SG). Founding member of the Virtual Laboratory of Cognitive, Affective and Behavioral Neuropsychometry LAVINAC. Member of the Municipality of Rio de Janeiro. Ad hoc referee of the Brazilian Society of Social Psychology, Ad-hoc consultant-Federal University of Paraná, He was a referee at the Symposium on Excellence in Management and Technology. Responsible for the PPC of the Hospital Management and Psychology Courses in face-to-face and distance learning modalities. Professor and contentist in the distance modality since 2006 . He has experience in Psychology and Management, with an emphasis on Educational Management, Human Development Psychology, working mainly on the following topics: beliefs, stereotypes, adolescence, attitudes and HEI Management.

Volume 11 Issue 1, January 2022

www.ijsr.net

Licensed Under Creative Commons Attribution CC BY 